\title{
Family Mode Deactivation Therapy as a Manualized Cognitive Behavioral Therapy Treatment
}

\author{
Jack A. Apsche, Christopher K. Bass \& Marsha-Ann Houston
}

\begin{abstract}
This article examines the effectiveness of Mode Deactivation Family Therapy (MDT) in an outpatient setting as compared to Treatment as Usual (TAU). MDT is an evidence-based psychotherapy and has been shown to be effective treating adolescents with a variety of problems involving emotional disorder, physical and sexual aggression, as well as behaviors associated with anxiety and trauma. In this study, MDT was shown to be superior to TAU in an outpatient setting with improving family relationships and reducing family disharmony of the previous described adolescents.

Keywords: Mode Deactivation Therapy (MDT), Treatment as Usual (TAU), MDT Family Therapy.
\end{abstract}

\section{Introduction}

Mode Deactivation Therapy (MDT) has been shown to be an effective treatment for a variety of adolescent disorders (Apsche, Bass, \& Siv, 2006). Disorders that MDT has been shown to be effective with include emotional (Apsche \& Ward-Bailey, 2004) behavioral(Apsche, Bass, \& Murphy, 2006), physical aggression (Apsche, Bass, \& Houston, 2007), sexual aggression (Apsche, Bass, Jennings, Murphy, Hunter \& Siv, 2005), and many harmful symptoms of anxiety and traumatic stress (Apsche \& Bass, 2006).

MDT Family Therapy has been effective in reducing family disharmony in case studies, (Apsche \& Ward, 2004) and has been shown to be efficacious, as compared to Treatment as Usual (TAU) in treating families with a variety of problem behaviors (Apsche \& Bass, 2006) and in reducing and maintaining treatment effects thru 2 years of tracking recidivism rates (Apsche, Bass, \& Houston, 2007).

Apsche, Bass and Siv, (2006) completed a Family MDT clinical study of 14 adolescents with problems with sexual and physical aggression and oppositional behaviors, such as not following parent's direction, oppositional and verbal aggression. The results suggest that MDT out-performed Treatment As Usual (TAU); at the eighteenth month of observation, the MDT group had zero sexual recidivism, while the TAU group had 10 reported incidents or problems with sexual behavior. The MDT group reported 3 incidents of physical aggression while the TAU group reported 12 incidents.

The results were promising for MDT as a Family Therapy, but the small size of the group rendered the effects of the study as having some limitation, and in need of further study with a larger group; however, results are suggestive of a promising methodology.

Apsche, Bass, and Houston (2007) completed a study of Family MDT with an additional 8 families in the community, as compared to a separate TAU group. The Apsche et. al. (2007), study examined physically aggressive youth with personality and conduct problems. The study had a total of 15 families, 8 in the MDT group and 7 in the TAU group. MDT out-performed TAU at the twenty week interval of treatment. The most compelling point of data was that the MDT group had zero referrals for "out-of-home placements", while the TAU group had referrals fore FOUR? out-of-home placements. The results are promising, yet the small number of participants limits the claims of the effects of Family MDT. 
A major problem of treatment research is that large adequate sample sizes are not always available. Referred clients and families are "sent" for treatment. The "sent" client or families, by nature, usually enter treatment with a level of resistance. The resistance is based on the issue that someone else determined that there are problems within the family. The sources of these referrals are typically a court or department of Children and Youth. The clinician or researcher has to find a strategy to motivate the family to work hard to address their issues and problems.

MDT, both in individual and family work, offers the therapist and client(s) the ability to collaborate and learn; structure, measure and track progress in treatment in the Family Manual (Apsche \& Apsche, 2007).

MDT is an individual and family manualized treatment that incorporates treatment strategies from behavioral, cognitive, dialectical, and other supportive psychotherapy approaches. It is administered according to the MDT Clinicians Manual. MDT includes weekly individual and group therapy sessions, provided on an average of 8 to 12 months, depending upon the level of cooperation and amenability to treatment of the individual and families.

MDT individual or family treatment process starts with an exhaustive case conceptualization. Tools used in the individual and family case conceptualization include a diagnostic interview, behavioral history and complete family history, identified as the typology survey. Following the typology survey, the individual and family assessments are determined by responses and the level of conduct issues of the adolescent. MDT uses a continuum from reactive to proactive as a successive scale of 1 to 10. The adolescent and/or family that score a 3 and above is considered to be proactive and needs the specific assessments that apply.

The Fear Assessment is the basic assessment that addresses the individual's issues of anxiety, fear, and posttraumatic stress. There are five different assessments to choose from. The particular fear assessment chosen is based on the openness of the adolescent and his family. If they are not amenable to treatment and have multiple antisocial beliefs there is the "other" series of assessments. For more anxious and traumatic stressed families there is the "Fear-R." assessment, the Fear- Pro, Fear- Difficulty and Pro$\mathrm{R}$ and other assessments to suit the particular adolescent and his family.

The next assessment is the Compound Core Beliefs Questionnaire (CCBQ). The CCBQ is a 109 question assessment of the adolescent's beliefs as they relate to personality traits based on the work of Beck, Freeman, Davis \& Associates (2004).

Assessments are scored and used in the development of a thorough case conceptualization that includes a Functional Behavioral Analysis. This methodology is based on the Functional Analytic Psychotherapy methodology (Kohlenberg \& Tsai, 1993).

From the case conceptualization, the adolescent's treatment is determined. Similarly, the family case conceptualization is developed through assessments given to family treatment participants to determine the family's conglomerate of fears and beliefs.

The Functional Treatment Form is the framework of treatment. The validation $\rightarrow$ clarification $\rightarrow$ redirection process is the basic therapeutic methodology of MDT. The method validates "the grain of truth" in everything that the adolescent believes. His perception is then clarified. This is to help the client accept his beliefs and yet be more receptive to exploring another way of ultimately behaving by examining beliefs, in case there are other beliefs that might be possible. The redirection is actually a refrain and reinforcement for the adolescent to accept for that one moment, or that time only, there would be an alternative explanation or belief. For example, if a client has difficulty trusting others, and endorses 
this belief $100 \%$, "Everyone betrays my trust, I cannot trust anyone," he could be queried about his trust level for a particular person. If he trusts the identified person at a 2 or 3 out of a possible 10 , then he can easily be helped to see and agree that the person in question, at a 2 rating did not betray his trust for that moment. Therefore, it may be possible for him to trust that person at a level of 3 in the moment.

Consequently, he can be helped to balance his belief and conclude: "sometimes I can trust some people a little in the moment." In balancing his beliefs, the adolescent must be assisted to adapt alternative beliefs "sometimes."

\section{Control Group: Treatment as Usual (TAU)}

The TAU group methodology involved a collection of eclectic treatments implemented by doctorate level licensed psychologists in the geographical area. This area included, but was not limited to Philadelphia, PA and its surrounding counties. It is important to remember that individuals and families in this treatment-research were "sent." They were required to seek treatment as a result of Children and Youth investigators or court and legal demands.

Unlike many University and Grant founded research samples, where they can reject individuals there were "no" rejections of individuals or families permitting. Psychologists and therapists in both the MDT and TAU group were required to treat all individuals and their family that were referred. There was a "no reject" or "eject" policy in place for the entire length of treatment for both groups.

Often grant funded university based researchers have the opportunity to "select" subjects based on a extremely narrow set of diagnostic and selection criteria. Their narrow selection criteria might boost their effects and results as compared to treatment research studies (Kazdin \& Weisz, 2003).

\section{Method}

Clients were randomly assigned to the MDT (20) and TAU (20) groups by Children and Youth Services. Assignments were made on a rotating basis, for all participants, randomly. Psychologists of each group had no access to the trial participants prior to assignment and referral. No client or family was selected by the therapist or the participants.

All participants were informed that they were participants in a treatment research study and they all individually consented to actively participate in this study. American Psychological Association guidelines were adhered to for protection of subjects. Clients and all family members agreed to participate, with assurances that their anonymity would be preserved.

MDT Family Therapy also examines the "process" of family interactions (Apsche \& Bass, 2006; Apsche \& Ward, 2003). MDT attempts to move the family to use a new script, based on the collective case conceptualization process (Apsche \& Bass 2006; Apsche \& Ward, 2003).

Unlike Multisystematic Therapy (MST), as delineated by Henggeler et al., (1998) which would focus on the youth as embedded in multiple systems that have basic direct and indirect influences on his or her behavior, MDT focuses on the system of family beliefs and modes based on the collective and individual modes of family members. MDT is more of a psychotherapeutic intervention rather than a system of treatments. One therapist is central to the individual, group and family process. The therapist is the team captain and coordinates individual, family, and group psychotherapy. 
Most Cognitive Behavioral treatment has a focus on the individual client, who in this case, is the adolescent (Apsche \& Jennings, 2007). The MDT process focuses first on assessment and case conceptualization of the adolescent, followed by the completion of the family case conceptualization. MDT includes a family workbook (Apsche \& Apsche, 2007) and exercises which help to reintegrate the troubled youth and his/her family and extended family.

To avoid individualized stigma (Apsche \& Apsche, 2007; Apsche \& Bass, 2006; Apsche \& Ward, 2004) the MDT Family Fear and Belief Assessments were created. These assessments determine the collective family case conceptualization. This allows the MDT therapist to interpret his/her treatment approach as stemming from an empirically derived methodology.

MDT Family Therapy is designed as an extension of the MDT methodology for adolescents (Apsche \& Bass 2006; Apsche \& Ward, 2004). This approach is not designed for implementation as a separate methodology but is to be implemented as part of MDT treatment for adolescents.

MDT Family Therapy was initiated in this study, by accomplishing the Family MDT assessments. The Family MDT assessments resemble the in dividual MDT assessments. The Family MDT methodology includes a Family MDT Workbook. This workbook is derived to structure the Family Therapy, following an MDT methodology. The workbook is designed to provide a collaborative effect for all family members. The Family MDT Manual addresses the following topics:

- Family Commitment to Treatment

- Responsibility for The Family

- Family Belief Analysis (Compound Core Beliefs)

- Modes of the Family

- MDT and Reactive Anger, Aggression, and Impulse Control

- Your Family's Beliefs and Problem Behaviors

- Problem Behaviors and MDT

- Substance Abuse in Your Family

- Empathy for the Family

- Becoming Survivors

1) The Fear-Family assessment is an assessment of 60 items that identifies basic difficulties, anxieties, or fears of the family. Each family member completed the assessment, and the scores were totaled and a mean score was determined across each item.

2) The Family Core Belief Assessment is an inventory of 96 questions related to the familiar belief systems. The Family Core Belief Assessment was scored in the same manner as the Family Fear Assessment.

3) The Functionally Based Treatment Development Form is a form that addresses the collective family beliefs and supplies the family a specific methodology to develop and maintain more functional family beliefs.

The families were taught how to balance their beliefs with the V-C-R method. V-C-R is a methodology of validation, clarifying, and redirecting the belief of the family. While there may be some identification of opposing beliefs, this method attempts to expose the irrational, illogical beliefs deeply held by families in crisis. The individual components of the V-C-R method included: 
Validation. Each family member's thoughts and beliefs were validated initially. Therapists searched for grains of truth in each family member's responses. It was important to assure each member that his/her responses were accurate as far as his/her interpretation of his/her perceptions. Each member was given appropriate reinforcement that (s)he was certain that (s)he fully understood and believed.

Clarification. Therapists clarified the content of responses. Therapists also clarified the beliefs that were activated. It was important that clinicians understand and agreed with the content of the clarification. The Clarification step was crucial in understanding the long held thinking schemas. This was clarification of the member's perspective or reality and beliefs.

Redirection. Therapists redirected responses, to view other possibilities or the continuum of held beliefs. The goal of this step was to help the family member find the exception in the belief system. The redirection involved examining the opposite side of the dichotomous or dialectical thinking. It was crucial to partner with the member to see the "grain of truth" in each of the dichotomous situations presented.

\section{Chart 1: Diagram of the Dysregulation Process}

$$
\begin{aligned}
& \text { Adolescent's Belief } \leftarrow-------------D y s r e g u l a t i o n------------~ \rightarrow \text { Other's Belief or } \\
& \text { Source of Conflict }
\end{aligned}
$$

Family Belief \#1 $\leftarrow$-----------------Dysregulation---------------- $\rightarrow$ Family Belief \#2

\section{Dichotomous Belief}

\section{Integrated Family Belief \#1 $\leftarrow-----$ VCR---- $\rightarrow$ Integrated Family Belief \#2}

Chart 1 highlights the direction of the deregulated belief system. The redirection was an attempt to aid the youth and family member in seeing both sides of the dichotomous belief(s). Also important was to look for the truth in each and compromise in understanding the truth in both beliefs. The use of a continuum of belief was implemented to examine the individual's belief of truth in both of the dichotomous beliefs and situation.

Each individual in the family, as well as the family collectively completed the Conglomerate of Beliefs and Behaviors (COBB). The COBB examined each individual's belief as well as their corresponding behaviors. Once the family's Beliefs and Behaviors were determined, they were compared to each individual's beliefs and behaviors.

These methodologies addressed the specific behaviors of each family member and contrasted it to the families score. The behaviors were explained and understood as the individual integrated their beliefs and behaviors within the family system at large. 


\section{Timing Assessments}

Assessment were timed prior to pre-treatment and at end point 8 months, and at 2 years posttreatment. All individual participants were tracked with behavior report sheets in school and at home measures. All adolescents were administered the Child Behavioral Checklist (CBCL) parent form.

Families were assessed by behavior report sheets that measured verbal and physical aggression, arguments, and "not attending behavior." These home attending behaviors were defined as any behaviors by the parent or adolescents that would prohibit verbal engagement, such as non-compliance, walking away, or not responding to requests.

Chart 2: Pre-Treatment Beliefs

\begin{tabular}{|c|c|c|c|c|c|c|c|c|}
\hline $\begin{array}{l}\text { Adolescent's } \\
\text { Beliefs }\end{array}$ & Behavior & 焉 & $\begin{array}{l}\text { Mother's } \\
\text { Beliefs }\end{array}$ & $\begin{array}{l}\text { Ta } \\
\stackrel{3}{0} \\
\stackrel{0}{0} \\
0\end{array}$ & Behavior & $\begin{array}{l}\text { Sibling's } \\
\text { Beliefs }\end{array}$ & Behavior & $\begin{array}{l}\text { Pre- } \\
\text { Treatment }\end{array}$ \\
\hline $\begin{array}{l}\text { Life at times } \\
\text { feels like an } \\
\text { endless series of } \\
\text { disappointments } \\
\text { followed by pain. }\end{array}$ & $\begin{array}{l}\text { Isolation } \\
\text { (physical \& } \\
\text { verbal } \\
\text { withdrawl) }\end{array}$ & 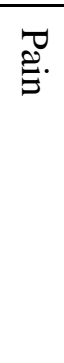 & $\begin{array}{l}\text { Whenever } \\
\text { I get } \\
\text { angry my } \\
\text { emotions } \\
\text { go from } \\
\text { annoyed } \\
\text { to } \\
\text { furious. }\end{array}$ & 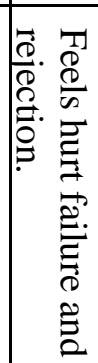 & $\begin{array}{l}\text { Screams } \\
\text { that he is } \\
\text { a freak } \\
\text { and } \\
\text { ruining } \\
\text { his/her } \\
\text { life. }\end{array}$ & $\begin{array}{l}\text { Whenever I } \\
\text { hope, I will } \\
\text { be } \\
\text { disappointed }\end{array}$ & $\begin{array}{l}\text { Tell } \\
\text { mother } \\
\text { he } \\
\text { smokes } \\
\text { pot and } \\
\text { drinks. } \\
\text { Fxxx off. }\end{array}$ & $\begin{array}{l}\text { Whenever } \\
\text { we feel in } \\
\text { this family } \\
\text { it is a } \\
\text { problem. } \\
\text { Family is } \\
\text { splintered. }\end{array}$ \\
\hline
\end{tabular}

The beliefs of this family, including individual and family beliefs, are reinforced by the feelings and behaviors of the individuals and the family. The family is so emotionally fragile that one negative belief, feelings, or behaviors sets a chain of negativity for the individuals and the family as a group.

The MDT therapist validates the beliefs as the individual's and family's reality. This is the radical acceptance of the beliefs as real as they exist in their world(s).

The search for clarification for the alternative belief that might be possible in this situation, "It might be possible in a situation, even for a moment, that life might not be a disappointment, followed by pain. Given that you (the adolescent) said when you paint you are "OK at that moment," on a scale of 1 to 10 , how much could that be possible, given that you are in therapy and able to express that ("at times") you feel like you are OK and actually might for a moment love your family. The adolescent responded that when he paints he is "OK at that moment." On a scale of 1 to 10 he is at a 7 when he paints. The MDT therapists then suggests, "If that is a 7 then you might not feel you 'always' feel like life is a series of disappointments followed by pain as a 4 or always every moment. He agreed that is true when he is practicing his art.

Once the adolescent responds a 2 or better, you have "redirected and reinforced" a possible alternative belief. The collective family beliefs addressed their Conglo merate of Beliefs and Behaviors (COBB). The family process is examining the family belief, "When we feel, it will be unpleasant." 
The family V-C-R process looks at the collective belief on a scale of 1 to 10 that there, "could be a time, a moment, that the family might experience a "positive feeling' for a moment." They talked about how, on the recent birthday of the sibling, they went to a theme park and all "had a ball" together. The collective scale of 1-10, was a 4 that at times the family can feel that it is positive, been a good feelings collectively. The MDT therapists helped the family address a belief and synthesize agreement that "At times we can feel as a family and it can be pleasant." The V-C-R allowed the family to accept their beliefs as their reality, clarify how the belief translates to them individually and as a family, and redirected them to an alternative belief they might be real; four (4) out of 10 times, in this session. The collective experience of the family can slowly begin to move to healthier, collective beliefs to balance the family's belief systems.

Chart 3: Balanced Beliefs

\begin{tabular}{|c|l|l|l|}
\hline $\begin{array}{c}\text { Adolescents } \\
\text { Balanced Beliefs }\end{array}$ & \multicolumn{1}{c|}{ Mother } & \multicolumn{1}{c|}{ Sibling } & \multicolumn{1}{c|}{ Family } \\
\hline $\begin{array}{c}\text { At times life can be } \\
\text { OK and not painful. }\end{array}$ & $\begin{array}{l}\text { Whenever I get } \\
\text { angry I can balance } \\
\text { my anger at times. }\end{array}$ & $\begin{array}{l}\text { I can hope } \\
\text { sometimes and be } \\
\text { satisfied. }\end{array}$ & $\begin{array}{l}\text { The family out of } \\
\text { 4-10 times is } \\
\text { positive. Can feel } \\
\text { OK 3 out of 10 } \\
\text { times with my } \\
\text { family. }\end{array}$ \\
\hline
\end{tabular}

\section{Results}

The results of this study suggest that MDT was more effective than TAU with adolescents and their families in reducing arguing, displays of anger, physical and sexual aggression and placement in more restrictive, long term, out-of-home settings. MDT also out- performed TAU in recidivism for two (2) years post-treatment.

Important and revealing data is the fact that the number of referrals for out-of-home placements for a 2-year post-treatment for the MDT group was one (1), as opposed to the TAU group which was 14.

The MDT group had one (1) adolescent referral to a group home and another adolescent referral to an acute care placement in a psychiatric facility. The TAU group had 4 adolescent referrals and placements in group homes, 8 referrals and placements in residential treatment facilities, and 2 referrals in acute psychiatric facilities.

Chart 4: Placement in Higher Level Care in a Two (2) Year Post-Treatment

\begin{tabular}{|l|c|c|}
\hline & MDT & TAU \\
\hline Group Homes & 1 & 4 \\
\hline Residential & 0 & 8 \\
\hline $\begin{array}{l}\text { Inpatient hospitalizations for } \\
\text { emotional issues }\end{array}$ & 0 & 2 \\
\hline
\end{tabular}


Sexual and aggressive behaviors, as defined and including, fondling, fellacio, deviant sexual intercourse and any other sexual behavior determined by the Children and Youth and/or the Court as illegal or problematic, or a charged defense.

Both Family MDT and TAU reduced the sexual behaviors. MDT reduced the sexually aggressive behaviors to zero and maintained zero (0) \% recidivism for two years post-treatment while TAU had $50 \%$ recidivism rate for sexually aggressive behaviors.

Chart 5: Pre-Sexual Aggression

\begin{tabular}{|cc|c|}
\hline \multicolumn{1}{|c|}{ MDT } & TAU \\
\hline Behaviors & 34 & 37 \\
\hline Post-8 Month Treatment & 0 & 15 \\
\hline \multicolumn{2}{|c|}{ Adolescents who engaged in sexual behavior. } \\
\hline \multicolumn{2}{|c|}{10} \\
\hline
\end{tabular}

Physical Aggression was the next targeted behavior for the adolescent. Family MDT helped reduce physical aggression more than $50 \%$ in 8 months and $21 \%$ of baseline the 2 year post-treatment date. Physical aggression remained relatively unchanged in the TAU group from 10 to 14 at the eight (8) month period and a fifteen (15) at the two (2) year eight (8) post treatments.

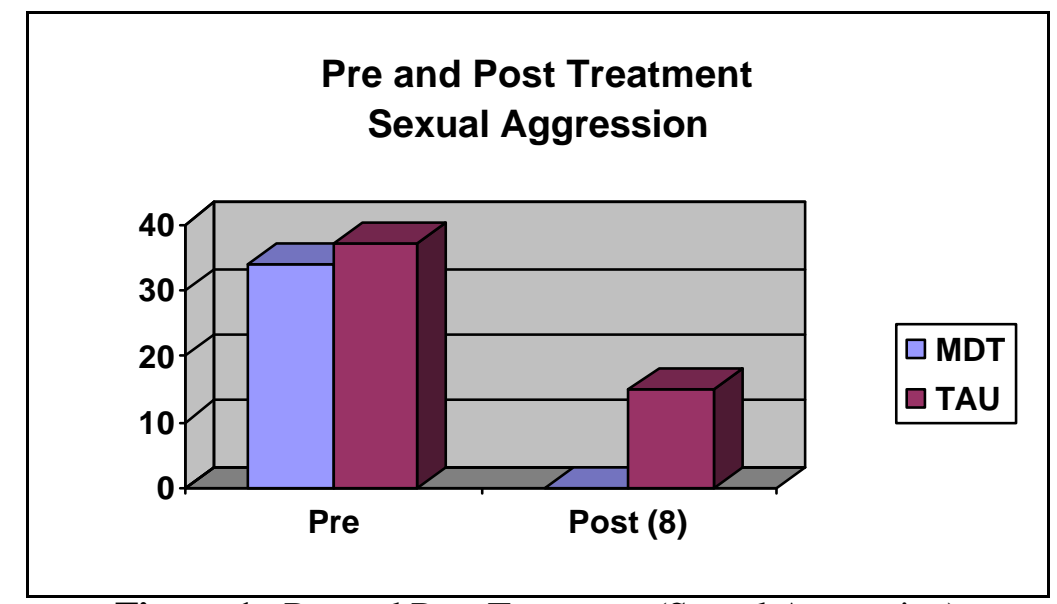

Figure 1: Pre and Post Treatment (Sexual Aggression) 
Chart 6: Ages 15-16 Physical Aggression

\begin{tabular}{|l|c|c|}
\hline MDT & TAU \\
\hline School Pre week & 17 & 16 \\
\hline Post & 6 & 14 \\
\hline Year & 4 & 15 \\
\hline
\end{tabular}

Verbal aggression or violent arguments were considered a clear antecedent of the physical aggression and other oppositional behaviors.

Chart 7: Weekly Verbal Aggression

\begin{tabular}{|c|c|c|}
\hline & MDT & TAU \\
\hline Pre & 47 & 48 \\
\hline Post & 12 & 36 \\
\hline 2 Year Follow-up & 8 & 39 \\
\hline
\end{tabular}

\section{Pre and Post treatment Verbal Aggression}

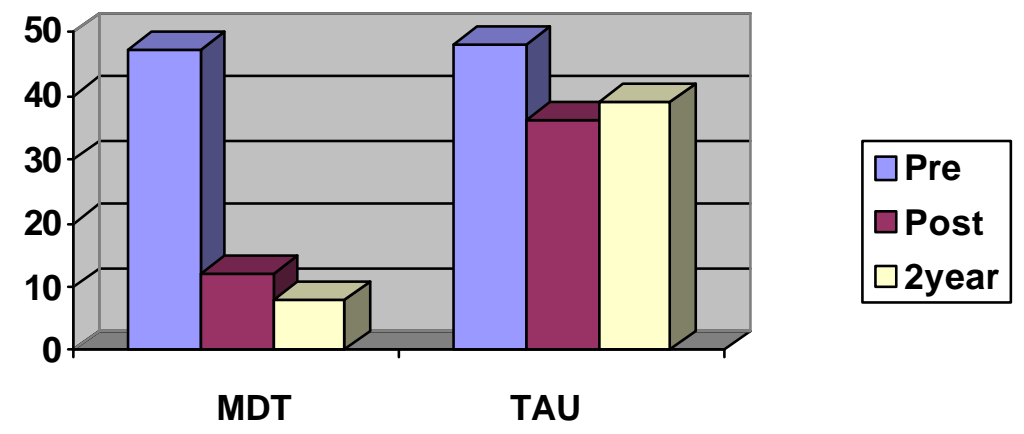

Figure 2: Pre and Post Treatment results (Verbal Aggression) 
Both MDT and TAU reduced sexual aggression at the eight (8) month of treatment. MDT's results reduced verbal aggression $77 \%$ from baseline; TAU reduced verbal aggression $24 \%$ from baseline. The 2 year post-treatment results show a continued decrease in the MDT group to $85 \%$ of baseline while the TAU group had a slight increase to $25 \%$ of baseline.

Chart: 8 CBCL

\begin{tabular}{|c|c|c|c|}
\hline Measure & Scale & TAU & MDT \\
\hline \multirow{3}{*}{$\begin{array}{l}\text { Child Behavior } \\
\text { Checklist (CBCL) } \\
\text { Pre-Treatment }\end{array}$} & Internal & $\begin{array}{l}72.27 \text { (Range }=68- \\
84)\end{array}$ & $\begin{array}{l}73.10(\text { Range }=66- \\
86)\end{array}$ \\
\hline & External & $\begin{array}{l}72.65(\text { Range }=68- \\
86)\end{array}$ & $\begin{array}{l}72.58(\text { Range }=64- \\
86)\end{array}$ \\
\hline & Total & 72.46 & 72.84 \\
\hline \multirow{3}{*}{$\begin{array}{l}\text { Child Behavior } \\
\text { Checklist (CBCL) } \\
\text { Post-Treatment }\end{array}$} & Internal & $\begin{array}{l}\text { 62.64 (Range }=55- \\
80) \mathrm{SD}=10.04\end{array}$ & $\begin{array}{l}56.58(\text { Range }=39- \\
\text { 71) } \mathrm{SD}=12.10\end{array}$ \\
\hline & External & $\begin{array}{l}\text { 68.25 }(\text { Range }=52-2 \\
\text { 82) SD } 1.76\end{array}$ & $\begin{array}{l}50.25(\text { Range }=37- \\
69) \mathrm{SD}=11.74\end{array}$ \\
\hline & Total & $\begin{array}{l}65.45(\text { Range }=52-84) \\
\mathrm{SD}=9.24\end{array}$ & $\begin{array}{l}50.17 \text { (Range }=40- \\
61) \mathrm{SD}+10.28\end{array}$ \\
\hline \multirow[t]{3}{*}{ Post- Treatment } & Internal & 69.34 & 47.86 \\
\hline & External & 66.34 & 46.38 \\
\hline & Total & 67.59 & 46.92 \\
\hline
\end{tabular}

The CBCL is a multiaxial assessment designed to obtain reports regarding the behaviors and competencies of 11 to 18 year olds. The means and standards are divided into three categories: internalizing (which measures withdrawn behaviors, somatic complaints, anxiety and depression), externalizing (which measures delinquent behavior and aggressive behavior), and total problems (which represent the conglomerate of total problems and symptoms, both internal and external). The results on the CBCL suggested that MDT was about 2 SDs more effective than TAU on Internal and External scales. MDT also showed a slight improvement at the two (2) year time frames, while TAU showed a slight increase. The final measure of this study based on the Juvenile Sex Offending Adolescent Protocol .II (Prentky \& Righthand, 2003).

The original version of this risk assessment scale for juvenile sex offenders was developed at Joseph J. Peters Institute (JJPI) in Philadelphia in 1994 (Prentky, Harris, Frizzell, \& Righthand, 2000). The risk assessment variables were developed after reviews of the literature that covered five areas: (1) clinical studies of juvenile sex offenders, (2) risk assessment/outcome studies of juvenile sex offenders, (3) risk assessment/outcome studies of adult sex offenders, (4) risk assessment/outcome studies from the general juvenile delinquency literature, and (5) risk assessment studies on mixed populations of adult sex offenders.

The results of the J-SOAP II suggested that Family MDT decreased the adolescents scores more than 1 SD more that TAU. The reduction of MDT was significant, whereas the TAU was a slight reduction of the J-SOAP II score. 
Chart 9: JSOAP-II Scores

\begin{tabular}{|c|cc|}
\multicolumn{1}{|c|}{ PRE } \\
\hline $\begin{array}{c}\text { MDT } \\
28 .\end{array}$ & & $\begin{array}{c}\text { TAU } \\
27 .\end{array}$ \\
\hline \multicolumn{2}{|c|}{ POST } \\
\hline \multicolumn{2}{|c|}{} \\
\hline MDT & TAU \\
18 & & 24 \\
\hline
\end{tabular}

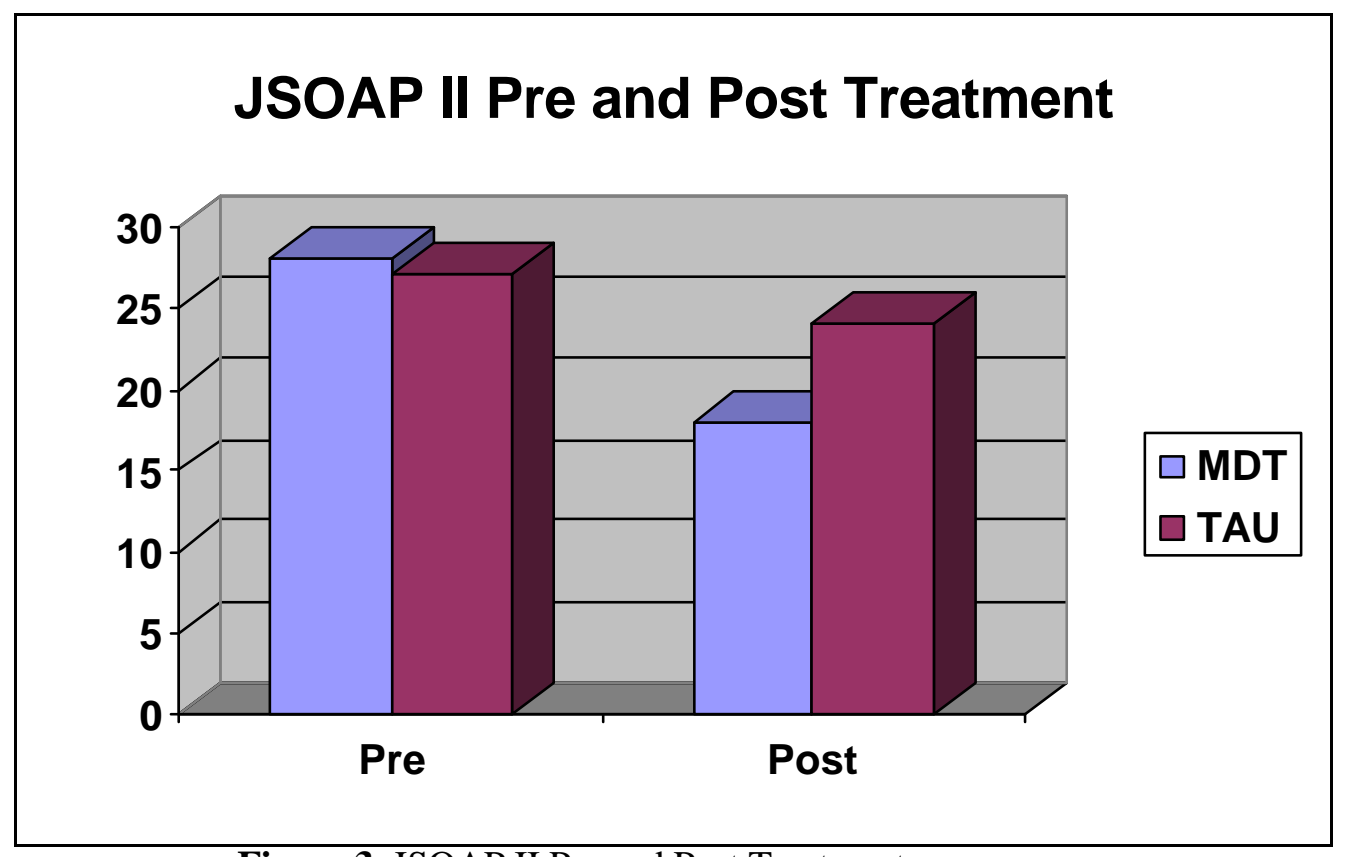

Figure 3. JSOAP II Pre and Post Treatment

\section{Discussion}

This study adhered to strict ethical, clinical, and research standards to treat and protect each participant with integrity and assurance of anonymity. Both the TAU and MDT groups were treated with dignity, respect, and assurance of ethical and clinical services. Through the comparison of Family MDT with Treatment As Usual in the community, five major results appeared.

First, we found significant results post-treatment for the MDT group to not be placed in a "higher level of care," or out-of-the-home. These results are signific ant on several levels. The adolescent was able to remain home and enrolled in school and receive adequate treatment. Second, Family MDT treatment saved the agencies hundreds of thousands of dollars for costly long term residential placement. At the minimal cost of $\$ 100,000$ per year, per adolescent, the savings might have been millions of dollars. 
Third the MDT group had no sexual aggression recidivism for two years post-treatment. The JSOAP-II scores were significantly reduced by the MDT group as well as, the sexually aggressive behavior.

Fourth, MDT appears to reduce internalizing and externalizing scores on the CBCL. This suggests that MDT/MDT Family might be effective in reducing both external behaviors, as well as symptoms of psychological distress. The games made by the adolescent on the CBCL appeared to generalize for two years post-treatment. The total scores were reduced and maintained their reduction for a two year period. This suggests the MDT had an effect on reducing behavior and psychological symptoms on "at risk" adolescents. They completed the CBCL for a post-treatment follow-up. They were prompted by telephone calls and emails (from one of the MDT team) to complete the forms.

Fifth, MDT Family decreased both verbal and physical aggression and maintained the decrease at an $85 \%$ reduction of baseline behavior.

The absence of significant pre-treatment differences between subjects who received MDT and control subjects on the same measures, together with the random assignment to condition, rules out interpretation of these results bound on known pre-existing differences.

This study suggests that a manualized CBT Family Therapy Methodology might be effective for "at risk" adolescents and their "family." Family might be defined as the adolescents' caregiver, and this might include biological parents, grandparents, relatives, and/or foster parent.

The underlying MDT methodology addresses the family's collective beliefs and thru V-C-R attempts to synthesize these beliefs into a collective agreement of more functional positive possibilities. Family MDT implements the radical acceptance of the individual and family belief as "their reality."

The results of this study are promising and suggest that the MDT Family methodology can be included with accepted, evidence-based psychotherapies for "at risk" adolescents and their families.

There were limits to this study as there are in all clinical "real world" studies. The sample size was small, there were 40 participants, and therefore claims of the efficiency of Family MDT must be made with caution.

Having stated these cautions, it is fair to suggest that MDT collectively has been shown to be an effective methodology for treating "at risk" youth in a variety of settings. The authors are currently preparing a summary article on MDT; the population of all MDT studies now is nearing 250 participants. Because of the on-going nature of MDT research, MDT might be considered as a possible effective treatment for "at risk" youth, as described in each study.

Family MDT has been effective in limited studies thus far, (Apsche, Bass, \& Houston, 2007; Apsche, Bass, \& Siv, 2006). This study further suggests the possible effectiveness of MDT as a manualized CBT for families of "at risk" adolescents.

The analysis in this article, though a small study group was involved, gives information that shows the MDT approach to be useful in an outpatient setting. The approach treats the individual and family using various tools of assessment and therapeutic interaction, in concert with each other. MDT has efficacy in decreasing negative behaviors in the adolescent and family members. Clinical limitations regarding research of this kind would be lessened with a larger target population. However, it is 
signific ant that the outcome of this study was encouraging, although not all participants were internally motivated. For a comprehensive review of literature on MDT see Houston, Apsche, \& Bass (2007).

\section{References}

Apsche, J. A. \& Apsche, M. B. (2007). Mode Deactivation Therapy family manual. Unpublished clinical manual

Apsche J. A. \& Bass, C. K. (2006). A review and empirical comparison of three treatments for adolescent males with conduct and personality disorder: Mode Deactivation Therapy, Cognitive Behavior Therapy and Social Skills Training. International Journal of Behavioral Consultation and Therapy, 2(2), 382-398.

Apsche J. A. Bass, C. K., \& Siv, A. M. (2006). A treatment study of suicidal adolescent with personality disorder or traits: Mode Deactivation Therapy as compared to Treatment as Usual. International Journal of Behavioral Consultation and Therapy, 2(2), 215- 223.

Apsche J. A., Bass, C. K., \& Houston, M. A. (2007). Family MDT vs. Treatment as Usual in a community setting. International Journal of Behavioral Consultation and Therapy, 3(1), 145153.

Apsche, J. A., Bass, C. K., Jennings, J. L., Murphy, C. J., Hunter, L. A., \& Siv, A. M. (2005). Empirical comparison of three treatments for adolescent males with physical and sexual aggression: Mode Deactivation Therapy, Cognitive Behavior Therapy and Social Skills Training. International Journal of Behavioral Consultation and Therapy, 1(2), 101-113.

Apsche, J. A., Bass, C. K., \& Murphy, C. J. (2004). A comparison of two treatment studies: CBT and MDT with adolescent male sex offenders with reactive conduct disorder and/or personality traits. Journal of Early and Intensive Behavior Intervention, 1(2), 179-190.

Apsche, J. A., Bass, C. K., \& Siv, A. M. (2005). A review and empirical comparison of three treatments for adolescent males with conduct and personality disorder: Mode Deactivation Therapy, Cognitive Behavior Therapy and Social Skills Training, International Journal of Behavioral Consultation and Therapy, 1(4), 371-381.

Apsche, J. A., Bass, C. K., \& Siv, A. M. (2006). Summary of Mode Deactivation Therapy, Cognitive Behavior Therapy and Social Skills Training with two year post treatment results. International Journal of Behavioral Consultation and Therapy, 2(1) 29-44.

Apsche, J. A. \& Jennings, J. L. (2007). Responsibility and self-management. Holyoke, MA: Neari Press.

Apsche, J. A., \& Ward, S. R. (2003). Mode Deactivation: A functionally based treatment, theoretical constructs. The Behavior Analyst Today, 4 (1), 47-58.

Apsche, J. A., \& Ward Bailey, S. R. (2004). Mode Deactivation Therapy: Cognitive-Behavioural Therapy for young people with reactive conduct disorders or personality disorders or traits who sexually abuse. In M.C. Calder (Ed.), Children and young people who sexually abuse. New theory, research and practice developments, (pp. 263-287). Lyme Regis, UK: Russell House Publishing. 
Apsche, J. A. \& Ward Bailey, S. R. (2004). Mode Deactivation Therapy (MDT) Family Therapy: A theoretical case analysis. Journal of Early and Intensive Behavior Intervention, 1 (2), 191-217.

Beck, A. T., Freeman, A., Davis, D.D., \& Associates. (2004). Cognitive therapy of personality disorders (2nd ed.). New York: Guilford Press.

Henggeler, S. W., Schoenwald, S. K., Borduin, C. M., Rowland, M. D., \& Cunningham, P. B. (1998). Multisystemic treatment of antisocial behavior in children and adolescents. New York: Guilford Press.

Houston, M. A., Apsche, J. A., \& Bass, C. K. (2007). A comprehensive literature review of Mode Deactivation Therapy. International Journal of Behavioral Consultation and Therapy, 3 (2), 271309.

Kazdin, A. E. \& Weisz, J. R. (2003). Evidenced based psychotherapies for children and adolescents. New York: Guilford Press.

Kohlenberg, R. J. \& Tsai, M. (1993). Functional Analytic Psychotherapy: A behavioral approach to intensive treatment. In O’Donohue, W., \& Krasner, L., (Ed.), Theories of behavior therapy: Exploring behavior change (pp. 638-640). Washington, DC: American Psychological Association.

Prentky, R. A., Harris, B., Frizzell, K., \& Righthand, S. (2000). An actuarial procedure for assessing risk with juvenile sex offenders. Sexual Abuse: A Journal of Research and Treatment 12 (2), 71-93.

Prentky, R. A., \& Righthand, S., (2003). Juvenile sex offender assessment protocol - II (J-SOAPII). Manual. Retrieved September 11, 2007, from http://www.csom.org/pubs/JSOAP.pdf.

Author's Note: This article originally was published in The Behavior Analyst Today, Volume 8, No. 3

\section{Author Contact Information:}

Jack A. Apsche, Ed.D., ABPP.

The Apsche Center for Evidenced Based Psychotherapy

E - Mail: Jackmdt@aol.com

Phone: 215-321-4072

Christopher K. Bass, Ph.D., Dept. of Psychology

207 Knowles Hall Clark Atlanta University

Atlanta, GA 30313

E - Mail: CBass@cau.edu

Marsha-Ann Houston, MHS

E - Mail: Mhouston1957@ hotmail.com 